\title{
Characteristics and influencing factors of Cretaceous reservoir in eastern depression of North Yellow Sea basin
}

\author{
Zhang Yinguo $^{1,2,3} \cdot$ Chen Qinghua ${ }^{1} \cdot$ Sun $\mathrm{Ke}^{1} \cdot$ Wen Zhenhe ${ }^{1,2} \cdot$ Xiao Guolin $^{1,2} \cdot$ Liang Jie $^{1,2} \cdot$ Zhao Qingfang $^{1,2}$. \\ Wu Shuyu ${ }^{1,2} \cdot$ Lei Baohua ${ }^{1,2}$
}

Received: 9 July 2021 / Accepted: 28 October 2021 / Published online: 4 January 2022

(c) The Author(s) 2022

\begin{abstract}
Cretaceous is the key exploration target layer in the eastern depression of North Yellow Sea basin, which has a good prospect for oil and gas exploration. Its huge oil and gas resource potential has attracted great attention from petroleum geologists. In this study, the main rock types, reservoir space types, petrophysical characteristics and main controlling factors of Cretaceous reservoir are studied through core observation, thin section identification, petrophysical analysis and scanning electron microscope observation. The results indicate that the main rock types of Cretaceous reservoir in the eastern depression of North Yellow Sea basin are lithic arkose, feldspar lithic sandstone, some feldspar sandstone and a small amount of lithic sandstone. The average porosity is $6.9 \%$, and the average permeability is $0.46 \times 10^{-3} \mu \mathrm{m}$, so Cretaceous reservoir in the study area has poor petrophysical characteristics and belongs to low porosity and low permeability reservoir. Cretaceous reservoirs in the study area mainly develop in secondary pores, which are dominated by dissolution pores (including intragranular pores, intercrystalline pores and cleavage pores), followed by fractures. The main factors affecting petrophysical characteristics of Cretaceous reservoir in the study area are provenance properties, sedimentation, diagenesis (including compaction, cementation and dissolution) and tectonism. The provenance properties and sedimentation are the prerequisite conditions affecting petrophysical characteristics. Petrophysical characteristics of feldspar sandstone of Cretaceous reservoir in the study area and lithic arkose are better than that of feldspar lithic sandstone. Both compaction and cementation reduce the porosity and permeability of Cretaceous reservoir in the study area and make petrophysical characteristics become poor, whereas the dissolution and tectonism play an important role in improving petrophysical characteristics of Cretaceous reservoir.
\end{abstract}

Keywords North yellow sea basin $\cdot$ Reservoir characteristics $\cdot$ Provenance $\cdot$ Sedimentation $\cdot$ Diagenesis $\cdot$ Tectonism

\section{Introduction}

The North Yellow Sea is an epicontinental sea sandwiched between the east of Liaodong Peninsula and the Korean Peninsula (Wenyong et al. 2006a). The North Yellow Sea basin is a Meso-Cenozoic basin in the north of the Yellow Sea of China, which is located among Liaodong Peninsula,

Zhang Yinguo

zhangyingguo0615@163.com

1 School of Geosciences, China University of Petroleum (East China), Qingdao 266580, Shandong Province, China

2 Qingdao Institute of Marine Geology, Qingdao 266237, Shandong, China

3 Laboratory for Marine Mineral Resources, Pilot National Laboratory for Marine Science and Technology (Qingdao), Qingduo 266237, China
Shandong Peninsula and the Korean Peninsula. The basin is oblong (Jiangqi et al. 2007). The North Yellow Sea basin presents the structural pattern of uplift depression alternation, which is the western depression, the mid-western uplift, the central depression, the eastern uplift and the eastern depression from West to East (Fig. 1). The East depression of North Yellow Sea in this study area is located in the east of North Yellow Sea basin, with an area of about $5000 \mathrm{~km}^{2}$. Since the 1960s, China began to conduct intermittent investigation and research on the North Yellow Sea (Wenyong et al. 2006a; Jie 2005), involving strata, structure, sedimentation, petroleum geological conditions, etc. (Lin et al. 2006; Wenyong et al. 2006b, 2009; Shiyoul et al. 2009; Li et al. 2009; Gao, et al. 2007; Min et al. 2016; Xiaoqiang et al. 2015, 2017; Jinping et al. 2015), but so far there has not made a breakthrough in industrial oil and gas flow. Since 2005, oil and gas exploration in the eastern depression of 
Fig. 1 Tectonic units of North Yellow Sea (After Yuan Shukun (Shukunl et al. 2010))

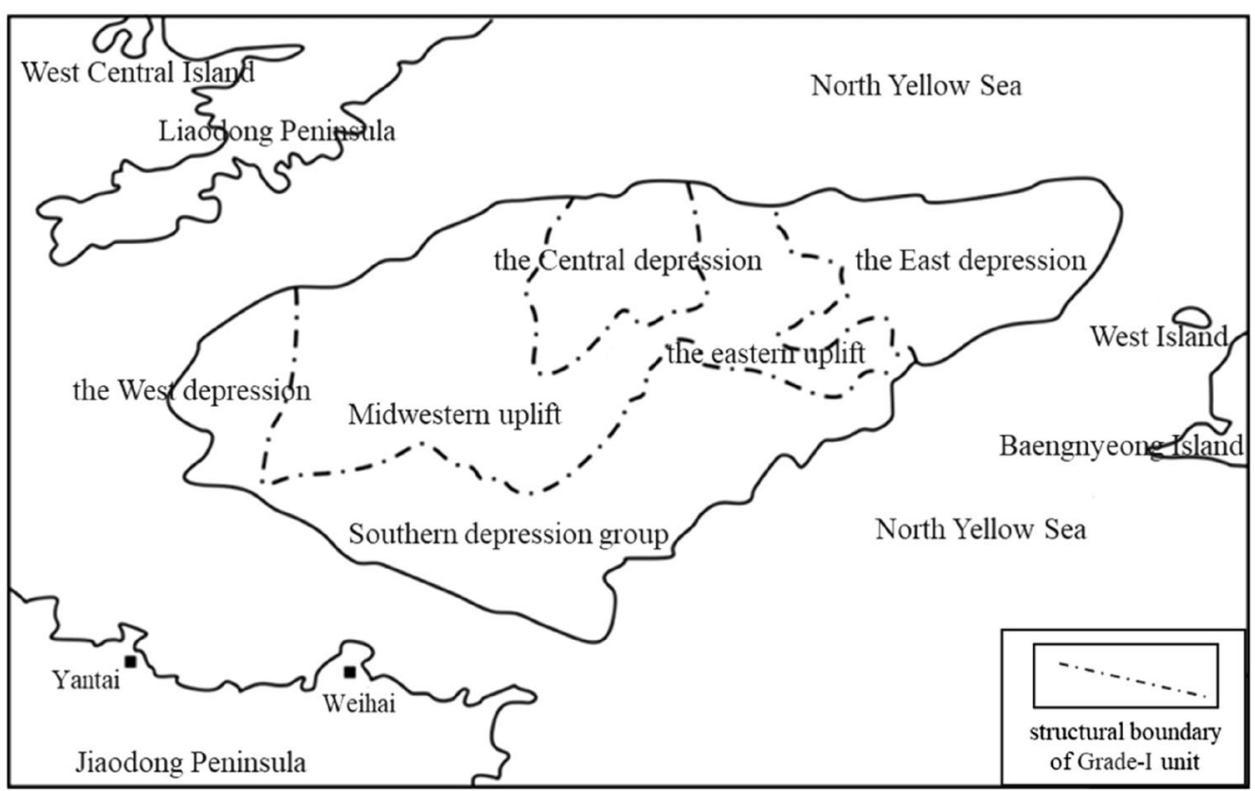

the North Yellow Sea has been strengthened. It is considered that the main source rock of Mesozoic in the North Yellow Sea basin is Jurassic. Oil and gas shows can be seen in Jurassic and Cretaceous for many wells, and low production oil flow can be obtained in Cretaceous for 6 wells, which indicates that the Mesozoic in the eastern part of the North Yellow Sea has certain exploration potential (Jinping et al. 2015; Zhenhu et al. 2014; Gai-yun et al. 2016), but the difficulty of exploration is the understanding of reservoir evaluation. Previous studies show that the Mesozoic in the North Yellow Sea mainly develops tight reservoirs (Sun et al. $2021 \mathrm{a}, \mathrm{b})$. In tight reservoirs, finding effective reservoirs is the key to achieve a breakthrough in oil and gas exploration in the North Yellow Sea. The in-depth understanding of reservoir characteristics and its controlling factors will provide a theoretical basis for finding effective reservoirs. Drilling in the eastern depression of the North Yellow Sea shows that the physical properties of the Cretaceous reservoir are better than those of the Jurassic, and the low oil production layers are concentrated in the Cretaceous (Wenyong et al. 2006a; Jiangqi et al. 2007). Therefore, in this study, the reservoir characteristics and main controlling factors of Cretaceous reservoir in the eastern depression of North Yellow Sea basin are systematically analyzed by means of rock sample test analysis and microscopic identification, which is of great significance for the Mesozoic oil and gas exploration in the North Yellow Sea.

\section{Regional geological background}

The North Yellow Sea basin is a Sino Korean platform, adjacent to Liaodong-Langlin uplift in the north and Jiaodong-Jingji uplift in the south. It is a Middle-Late Mesozoic strike-slip-rift basin superimposed on Proterozoic metamorphic rocks and Paleozoic marine residual strata, and the regional trend is north-east. Five wells in the eastern depression reveal the basement, which is mainly composed of Proterozoic metamorphic rocks, Cambrian and Ordovician carbonate rocks, and volcanic intrusive rocks in the northwest (Min et al. 2014). According to the regional tectonic evolution, the eastern depression experienced pre-rift stage, Mesozoic fault depression inversion stage, Paleogene fault depression inversion stage and Neogene regional subsidence stage (Ren et al. 2015; Zhanli et al. 2014). During the four stages of development and evolution, Jurassic, Cretaceous, Paleogene, Neogene and quaternary were developed above the pre Mesozoic in the eastern depression. The Jurassic mainly developed middle Jurassic and Upper Jurassic. Due to the tectonic uplift in the late Cretaceous, the middle and Upper Cretaceous are absent, and the lower Cretaceous is mainly remained. After the uplift and denudation in the late Cretaceous and long-term exposure, the Paleocene is not developed in the Paleogene, mainly from Eocene to Oligocene. According to the existing drilling data and seismic interpretation results, the maximum sedimentary thickness of the 
Mesozoic Cenozoic is $7200 \mathrm{~m}$, among which the maximum sedimentary thickness of the middle upper Jurassic is more than $2200-3000 \mathrm{~m}$, and the maximum sedimentary thickness of the lower Cretaceous is $1400-1600 \mathrm{~m}$. The lower Cretaceous is mainly composed of fluvial facies, braided delta facies, fan delta facies and shore shallow lake facies. The lithology is mainly thick mudstone, followed by sandstone and glutenite. The mudstone is mostly reddish brown and purplish red, and locally gray dark gray.

\section{Method}

For the study of Cretaceous reservoir in the eastern depression of the North Yellow Sea, rock mineral microscopic identification, reservoir physical property analysis, mercury injection experiment and scanning electron microscope analysis are mainly used, including 104 samples for rock mineral microscopic identification, 56 samples for reservoir physical property analysis, 21 samples for scanning electron microscope and 35 samples for mercury injection experiment. For each test, first select representative sandstone for experimental sample preparation and then conduct identification or analysis test. For the microscopic identification of rock and mineral, the cast body shall be poured first, and then the slice shall be made. The rock slice is to grind the rock sample into a grinder with a thickness of $0.03 \mathrm{~mm}$ and an area of about $20 \mathrm{~mm}$ by using emery of different particle sizes $\times 20 \mathrm{~mm}$ thin section and then identified by polarizing microscope to analyze rock mineral type, content, rock particle contact relationship and pore structure characteristics. The estimation of mineral percentage shall be within the error range required by SY / t5368-2003 industry standard. The rock sample for reservoir physical property analysis shall have a diameter of $2.5 \mathrm{~cm}$ and a length of $2.5-5.0 \mathrm{~cm}$ (or $3.8-7.6 \mathrm{~cm}$ ). It shall be tested by stl-iv core permeability tester and hxk-iii helium porosity automatic tester. The detection environment shall be $25{ }^{\circ} \mathrm{C}$ and $50 \%$ $\mathrm{RH}$. In the process of reservoir physical property analysis, the samples are first washed with oil and salt, dried, tested on the machine, filled with helium, and the permeability and porosity data are obtained. The measurement method is strictly in accordance with the standard gbt29172-2012 core analysis method. The mercury injection experiment is carried out by using the columnar sample of reservoir physical property analysis, and tested by poremaster 60 automatic mercury injection instrument, with temperature of $30{ }^{\circ} \mathrm{C}$ and humidity of $50 \% \mathrm{RH}$. The main process of mercury injection experiment is to select the dilatometer, load the sample, seal the dilatometer, weigh the dilatometer component of the loaded sample, low pressure analysis, high pressure analysis and clean the dilatometer. It is best to process the data to obtain the test data. The measurement method shall be in strict accordance with the standard GB / t21650.2-20,088/ iso15901-2:2006 mercury injection method and gas adsorption method for the determination of pore size distribution and porosity of solid materials. SEM analysis mainly uses electron beam with certain energy to bombard rock samples, so that electrons interact with samples to produce a series of identifiable information, and then collects, processes and scans and images the information in rocks with the help of high-power electron microscope, so as to complete rock structure, clastic mineral composition, authigenic cementation mineral composition, pore type identification and characterization of diagenetic phenomena. The scanning electron microscope was tested by qunta250feg field emission environmental scanning electron microscope. The detection environment was $20{ }^{\circ} \mathrm{C}$ and $45 \% \mathrm{RH}$. The experimental process of SEM analysis mainly includes oil washing, selection of observation surface, piling, drying, dust removal, coating, SEM observation and photography to form analysis results. The identification method is strictly in accordance with SY / t5162-2014 scanning electron microscope analysis method of rock samples and gbt-18295-2001 scanning electron microscope analysis method of sandstone samples of oil and gas reservoirs.

\section{Reservoir characteristics}

\section{Petrological characteristics}

The Cretaceous in the eastern depression of the North Yellow Sea is the main exploration target layer. At present, the Cretaceous is only the lower Cretaceous, which mainly develops two sets of reservoirs, namely the lower reservoir and the upper reservoir, and most of them are argillaceous sediments. The lithologic characteristics of the lower Cretaceous reservoir are mainly siltstone, kaolin siltstone, fine sandstone, gravel bearing fine sandstone, medium sandstone, coarse sandstone, glutenite and medium conglomerate, and the sandstone contains calcareous. The lower Cretaceous is mainly composed of lithic arkose and feldspar lithic sandstone, followed by arkose and some lithic sandstone (Fig. 2). The framework of sandstone consists of quartz, feldspar and lithic, in which feldspar is mainly potash feldspar. The main components of cuttings are extrusive rock, granite and quartzite, and other sedimentary rock cuttings include phyllite, schist, mudstone, sandstone, siliceous rock, carbonate rock and sand cuttings. The structural maturity of sandstone is low, and the sorting is mainly poor to medium, and some are medium to good. The grinding roundness is mainly subrounded and subangular, the particles are in line contact, and the cementation types are pore type and pressure embedded pore type. Sandstone cements are mainly composed of calcite and dolomite, followed by kaolinite and

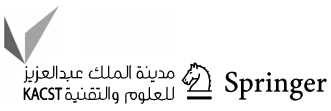




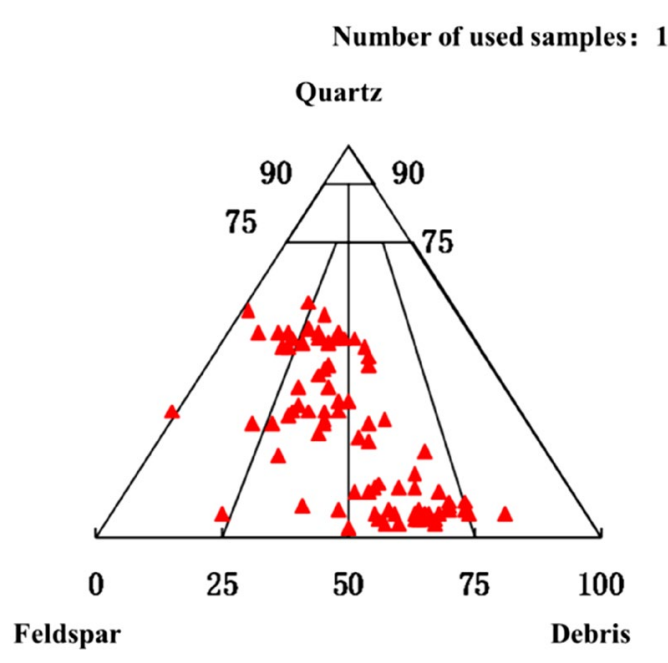

Fig. 2 Petrological characteristics of Cretaceous rocks in the East depression of North Yellow Sea

pyrite, and a small amount of siderite, siliceous and quartz. The content of calcite is generally $1-20 \%$, most of them are more than $3 \%$, and some of them are more than $20 \%$. The content of dolomite is generally $3-14 \%$, and most are above $5 \%$. The content of kaolinite is generally $0.5-3 \%$, and pyrite is about $0.5-2 \%$. And siderite, siliceous and secondary enlarged quartz are about $1 \%$. In addition, the matrix are mainly argillaceous, mainly in the range of $0.5-4 \%$, and a few more than $7 \%$.

\section{Reservoir pore types}

The pore types of Cretaceous reservoir are mainly secondary pores, followed by primary pores. The secondary pores are mainly intergranular pores, intragranular dissolved pores, intercrystalline pores, cleavage pores and fractures (Fig. 3 and Fig. 4), and the secondary pores are mainly dissolution pores. The primary materials forming dissolution pores are mainly feldspar particles, followed by volcanic feldspar debris. In addition, carbonate cements are mainly intergranular dissolution pores and calcite cleavage dissolution. Carbonate dissolution mainly occurs in the reservoir below $1300 \mathrm{~m}$ depth, but the degree of dissolution is far less than that of feldspar. The primary pores are relatively developed in the shallow layer and form intergranular pores. With the increase in depth, the primary pores decrease and the secondary pores increase. Most of the primary intergranular pores are more or less corroded in the later stage.

In this study, feldspar dissolution is an important reason for the formation of secondary pores and controlling physical properties of sandstone. The main pore types are selective dissolution pores, ribbed dissolution pores, intragranular pores and network dissolution pores. In addition to feldspar dissolution, the dissolution of feldspar in volcanic debris can also form intragranular pores. Also, the dissolution of carbonate cement is another reason for the formation of secondary pores, and the main pore type is intracrystalline pore. Carbonate dissolution mainly occurs in the reservoir below $1300 \mathrm{~m}$ depth, but the degree of dissolution is far less than that of feldspar, which often occurs between the two groups of calcite cleavage.

\section{Characteristics of reservoir pore structure}

The micro-pore structure parameters mainly include displacement pressure, average pore throat radius, median pressure, micro-homogeneity coefficient, mercury saturation and so on, which have good correlation with rock porosity and permeability and can directly reflect the characteristics of reservoir pore structure. The displacement pressure of Cretaceous reservoir is 0.211-19.642 $\mathrm{MPa}$, mainly in the range of 0.979-5.332 $\mathrm{MPa}$, with an average of $2.534 \mathrm{MPa}$. The median pressure varies greatly from 0.209 to $22.69 \mathrm{MPa}$, accounting for $52.42 \%$ of samples, and mainly in the range of 5.38-20.85 $\mathrm{MPa}$. The samples with median pressure greater than $27.638 \mathrm{MPa}$ account for $48.57 \%$, and the median pressure is mainly greater than $29.515 \mathrm{MPa}$. The average pore throat radius is $0.0251-0.674 \mu \mathrm{m}$. and $0.171 \sim 0.414 \mu \mathrm{m}$ is dominant. The micro-homogeneity coefficient is $0.027-0.787$, mainly in the range of $0.115-0.389$. The mercury saturation is generally $6.13-74.855 \%$, mainly in the range of $37.48-57.95 \%$. Therefore, from the above microscopic pore structure parameters, it is obvious that the lower Cretaceous reservoir generally shows high displacement pressure, small pore throat, dominated by small pore throat, poor connectivity, uneven distribution, small mercury intake, poor pore structure and strong heterogeneity.

\section{Physical properties of reservoir}

Based on the results of sandstone samples test analysis (Fig. 5), the porosity of Cretaceous reservoir is generally in the range of $2-10 \%$, with an average of $6.9 \%$. The porosity is concentrated in the range of $4-10 \%$, and a few can reach $10-16 \%$ which mostly in shallow layers of reservoir. The permeability is generally $0.02-2.05 \times 10^{-3} \mu \mathrm{m}^{2}$, and the average value is $0.46 \times 10^{-3} \mu \mathrm{m}^{2}$. The permeability is mainly less than $0.5 \times 10^{-3} \mu \mathrm{m}^{2}$, and a small amount is more than $0.5 \times 10^{-3} \mu \mathrm{m}^{2}$ where some of them can reach $2.0-6.5 \times 10^{-3} \mu \mathrm{m}^{2}$. Therefore, it can be seen that Cretaceous reservoirs in the eastern depression of North Yellow Sea basin have poor physical properties and are mainly low porosity, low permeability and even ultra-low porosity, ultralow permeability reservoirs. 


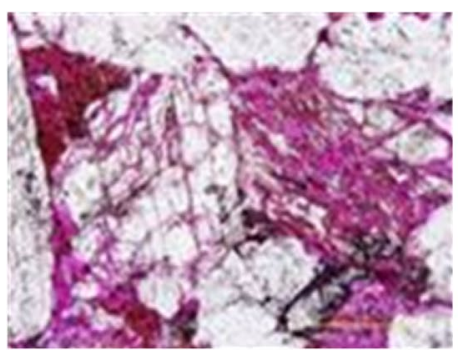

a Well 4 in $2219.89 \mathrm{~m}, 10 \times$ single polarized light. Intergranular feldspar cleavage pores and ribbed dissolution pores, filled and metasomatized by iron calcite. The particles are in point-line contact.

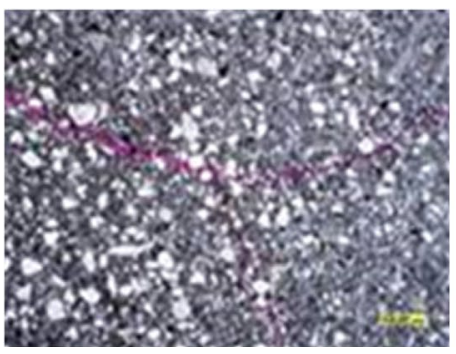

d Well 2 in $2966.97 \mathrm{~m}$, single polarized light. Fracture are developed.

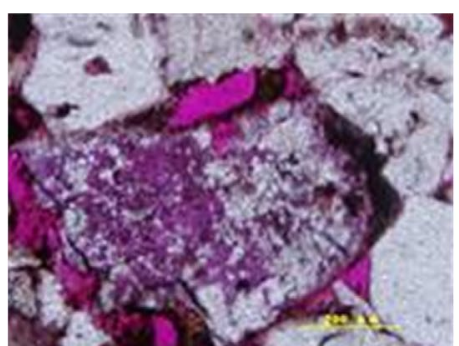

g Well 2 in $3046.23 \mathrm{~m}$, single polarized light. Calcite metasomatized feldspar and dissolved to form intragranular pores.
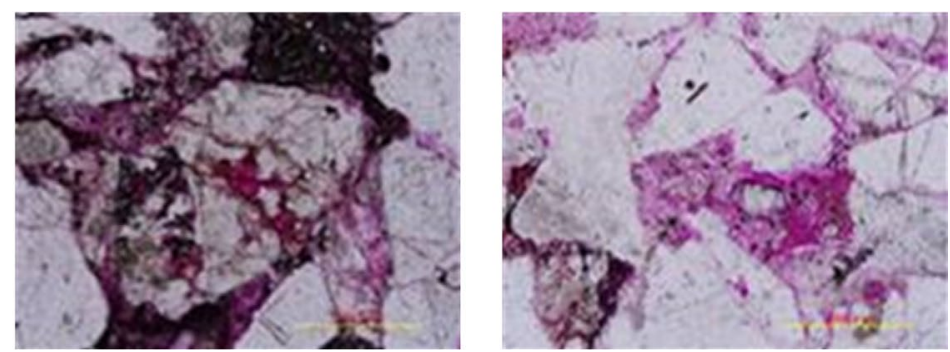

b Well 4 in $2220.34 \mathrm{~m}, 10 \times$ single polarized light. Feldspar dissolves along the cleavage direction to form intragranular solution pores, which are filled and metasomatized by iron calcite. The particles are in line contact.
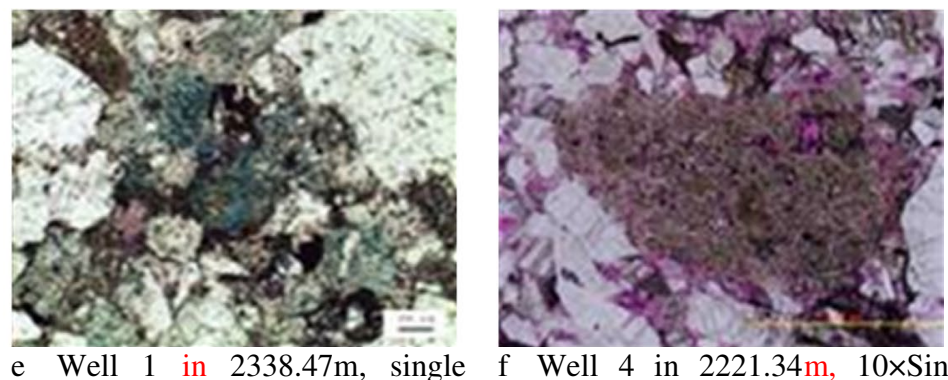

polarized light. Cement dissolved $\mathrm{f}$ Well 4 in $2221.34 \mathrm{~m}, 10 \times$ Single pore, and the particles are dissolved polarized light. Feldspar in volcanic debris dissolved to form intragranular into honeycomb with poor pores. Coarse grained lithic arkose. connectivity.

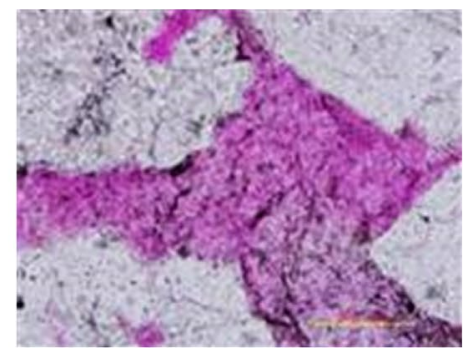

h Well 4 in 2219.89 m, 20xSingle polarized light. Intergranular pore of kaolinite. Medium coarse-grained lithic arkose.

dissolution pores and calcite
intracrystal pores are developed.
Calcareous medium fine-grained
feldspar lithic sandstone.

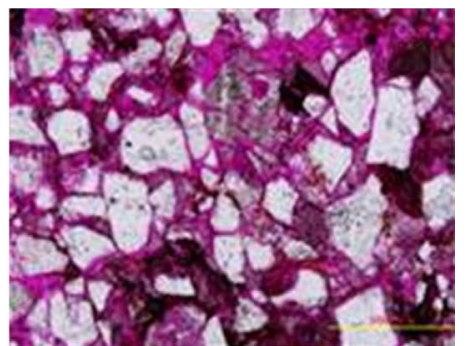

i Well 4 in $1330.08 \mathrm{~m}, 10 \times$ Single polarized light. Primary pores, feldspar cleavage pores, partial dissolution pores and calcite

Fig. 3 Cast thin sections showing pore types of Cretaceous reservoir in the East depression of North Yellow Sea 


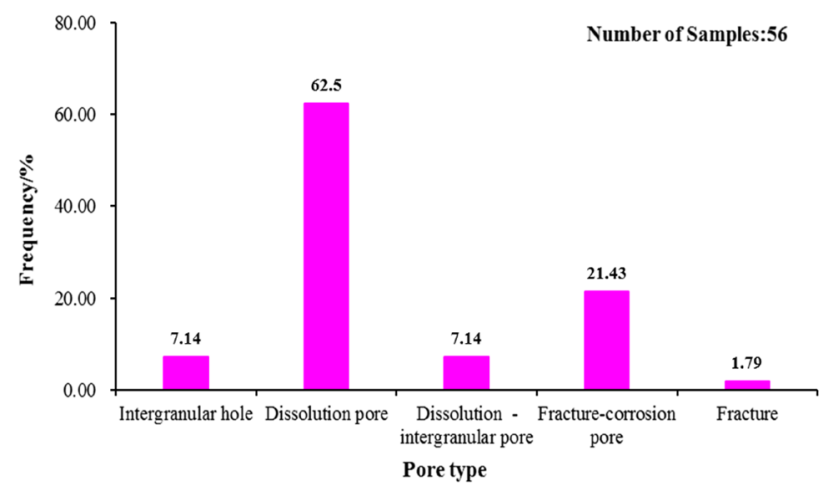

Fig. 4 Pore type distribution of Cretaceous reservoir in eastern depression of North Yellow Sea Basin

\section{Influencing factors of reservoir}

There are many factors that affect the physical properties of reservoir, which are mainly reflected in the provenance properties, sedimentation, diagenesis and tectonism of reservoir. Provenance properties and sedimentation determine the inherent conditions of reservoir materials. Diagenesis plays a role in destroying the physical properties of reservoir, while tectonism can improve them. Therefore, the superposition of various influencing factors results in the quality of the final reservoir physical conditions.

\section{Provenance properties}

Provenance property determines the petrological characteristics of the reservoir and thus, affects the reservoir performance (Sun et al. 2022). The characteristics of cretaceous sediments in different areas of North Yellow Sea

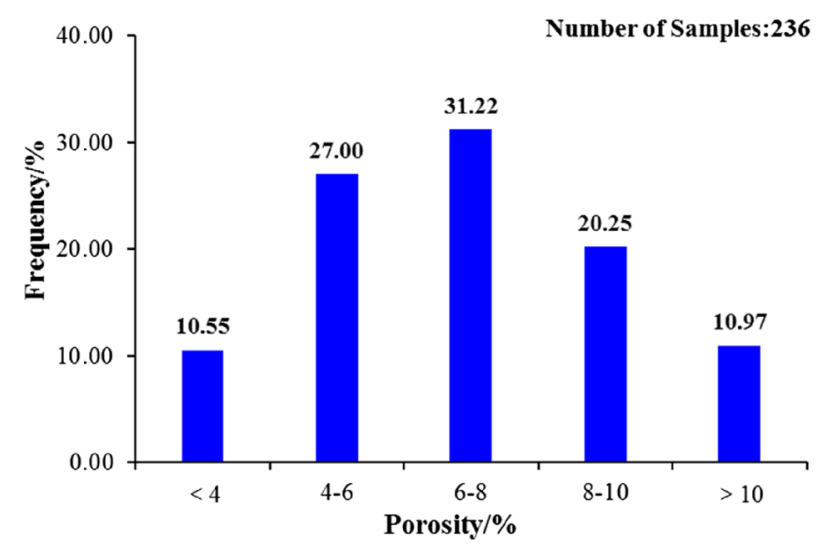

a Porosity distribution histogram
Basin are different. According to the analysis of heavy minerals from three representative wells (samples below the same depth of $2000 \mathrm{~m}$ ), there are three types of source materials. Firstly, it is the combination of metamorphic rock, acid granite and neutral-basic magmatic rock in well 1 , with high content of metamorphic rock and low content of garnet. Secondly, it is dominated by metamorphic rocks, with a small amount of intermediate basic magmatic rocks and acidic granite in well 2. Garnet is characterized by high content, ranging from 12.5 to $75.9 \%$. Ilmenite (also known as altered ilmenite), zircon and tourmaline ranges from 1.2 to $14.2 \%, 1.2 \%$ to $4.0 \%$, and $0.3 \%$ to $3.4 \%$, respectively. And zircon and electrical particles are mostly vertebral and columnar. Lastly, it is the metamorphic rock and medium basic magmatic rock assemblage of well 4, which is characterized by high content of garnet, hematite limonite and limonite, ranging from 13 to $62 \%, 27-34$ and $24-71 \%$, respectively. A small amount of acid granite with zircon content ranging from 0.2 to $4.0 \%$, and tourmaline content ranging from 0.2 to $0.5 \%$. And zircon and electric particles are mostly vertebral and columnar. Three different source material types form different reservoir petrological characteristics. Well 1 has a high content of feldspar, and the main rock types are arkose, lithic arkose, and a small amount of feldspar lithic sandstone (Fig. 6a). The lithological type of well 2 is mainly feldspar lithic sandstone and a small amount of lithic arkose (Fig. 6c). It is mainly composed of lithic arkose and feldspar lithic sandstone in well 4(Fig. 6e). Generally, the reservoir with high feldspar content is easy to be eroded and form secondary dissolution pores in the later diagenetic process (Shukunl et al. 2010), while the reservoir with high content of cuttings is strong in mechanical compaction and easy to become more compact, resulting in poor reservoir physical properties. And according to the actual physical

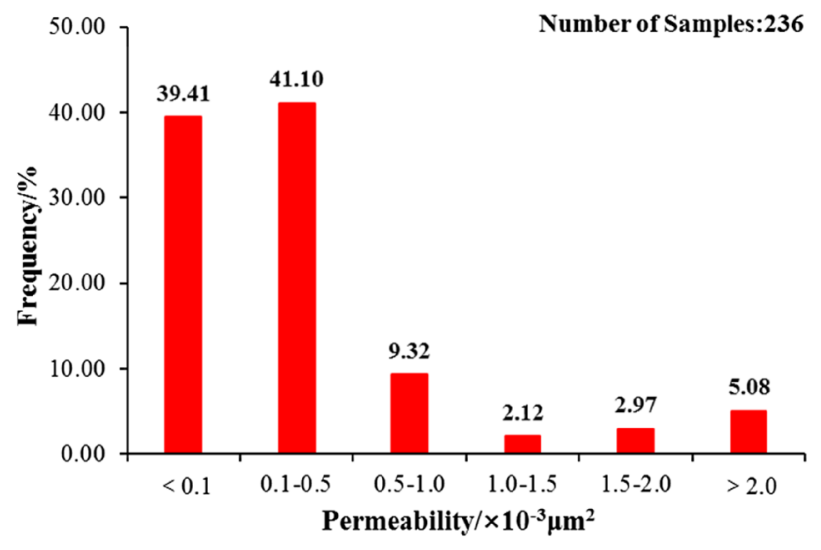

b Permeability distribution histogram

Fig. 5 Porosity and permeability frequency histogram of Cretaceous reservoirs in the East depression of North Yellow Sea 


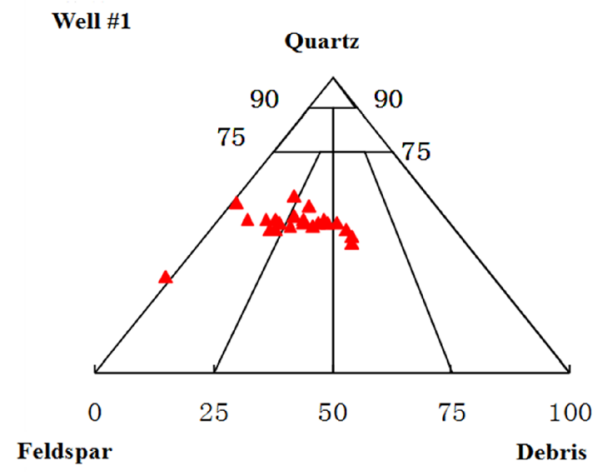

a Petrological characteristics in well \#1 Well \#2

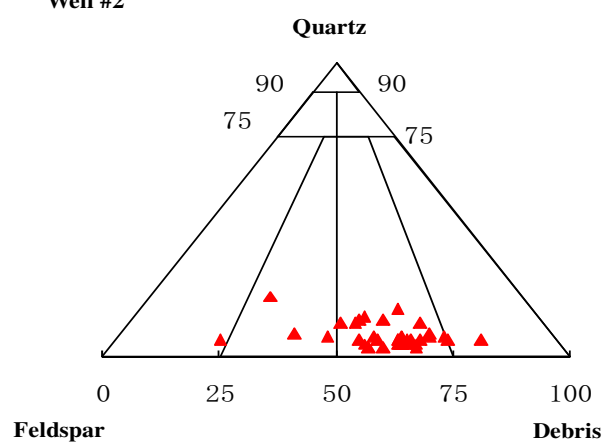

c Petrological characteristics in well \#2

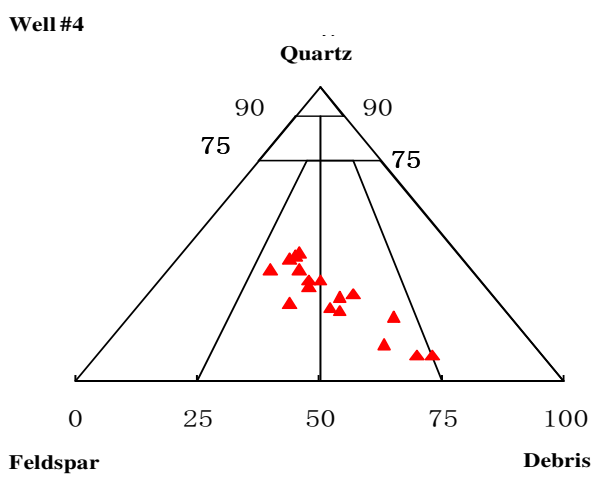

e Petrological characteristics in well \#4

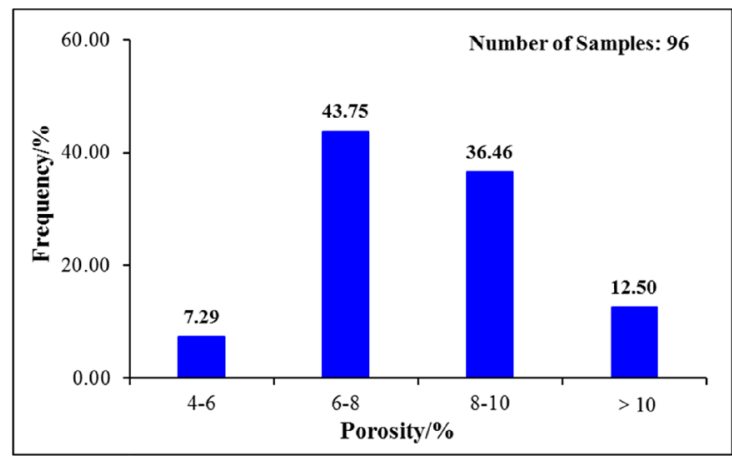

b Porosity distribution histogram in well \#1

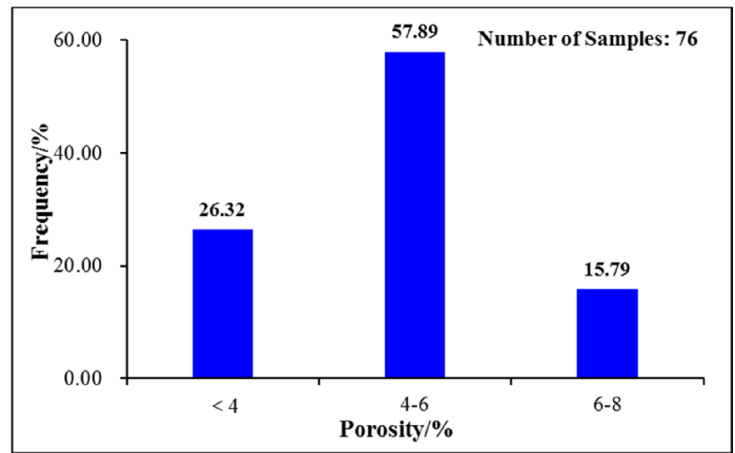

d Porosity distribution histogram in well \#2

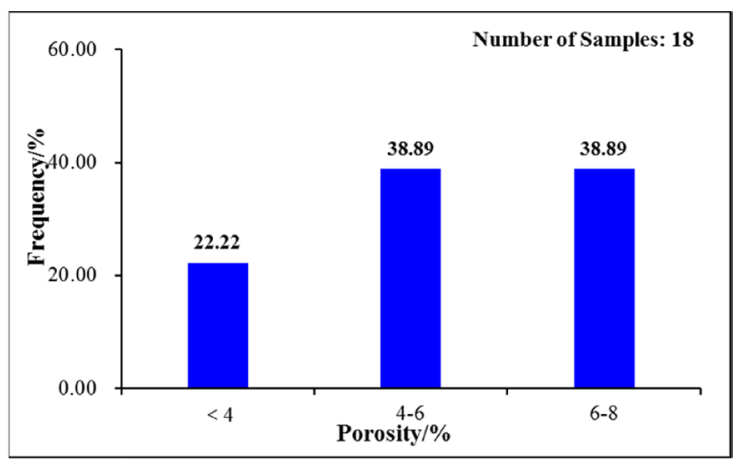

f Porosity distribution histogram in well \#4

Fig. 6 Comparison of petrological characteristics and porosity distribution of Cretaceous reservoirs in the eastern depression of North Yellow Sea

properties of three wells, it is also confirmed that the physical properties of well 1 are better (Fig. 6b), while those of well 2 and well 4 are relatively poor (Fig. 6d and Fig. 6f). The porosity distribution of well 1 is $4.2-14.9 \%$, with an average of $8.14 \%$, and the permeability is generally $0.04-2.1 \times 10^{-3} \mu \mathrm{m}^{2}$, with an average of $0.33 \times 10^{-3} \mu \mathrm{m}^{2}$. Well 4 takes the second place, and well 2 has the worst reservoir physical properties where the porosity ranges from 1.12 to $7.93 \%$, with an average of $4.77 \%$, and the permeability ranges from 0.02 to $6.58 \times 10^{-3} \mu \mathrm{m}^{2}$, with an average of $0.37 \times 10^{-3} \mu \mathrm{m}^{2}$.

\section{Sedimentation}

Sedimentary environment is the geological basis that affects the reservoir performance. There are obvious differences among reservoir performance of sandstone with different sedimentary microfacies (Feng and jie, Wang Duoyun, Xu Hui. the influential factors and 


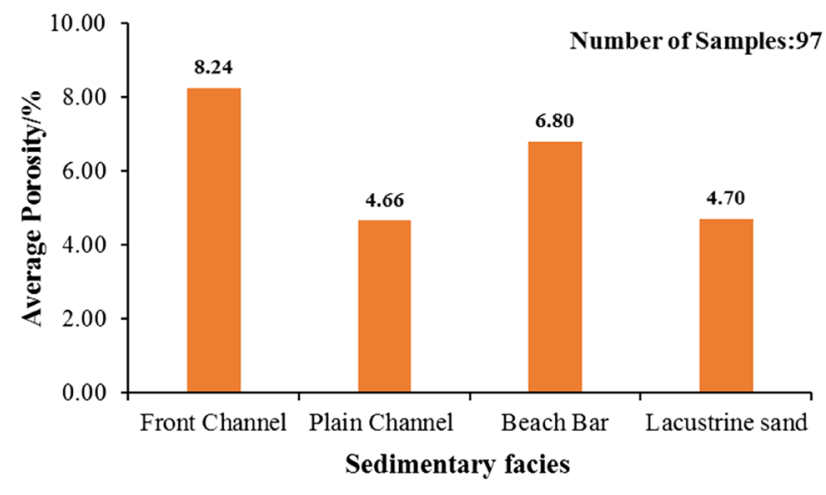

Fig. 7 Relationship between physical properties and sedimentary microflora of Cretaceous reservoir in well 1, eastern depression of North Yellow Sea Basin

characteristics of triassic yanchang formation reserviorin longdong area, ordos basin.2005, xxxx; Yanzhong et al. 2007; Yi et al. 2020; Sun et al. 2017). Grain size, sorting, rounding, cement and matrix are the main factors determining the original reservoir physical properties of coarse clastic sediments, which are all controlled by sedimentary environment, i.e., sedimentary facies (Yonghong et al. 2004; Sun et al. 2020). The Cretaceous sedimentary facies are mainly fluvial facies, braided delta facies, shore shallow lacustrine facies and shallow lacustrine facies. From the perspective of the corresponding relationship between sedimentary facies types and reservoir physical properties (Fig. 7), the physical properties of underwater distributary channel reservoirs in braided delta front are relatively good under strong hydrodynamic sedimentary conditions, but the physical properties of branch channel reservoirs with relatively weak hydrodynamic conditions in front or flank of front are relatively poor. The braided delta plain distributary channel and shore shallow lake sheet sand are relatively poor, and there has no test results of the fluvial facies.

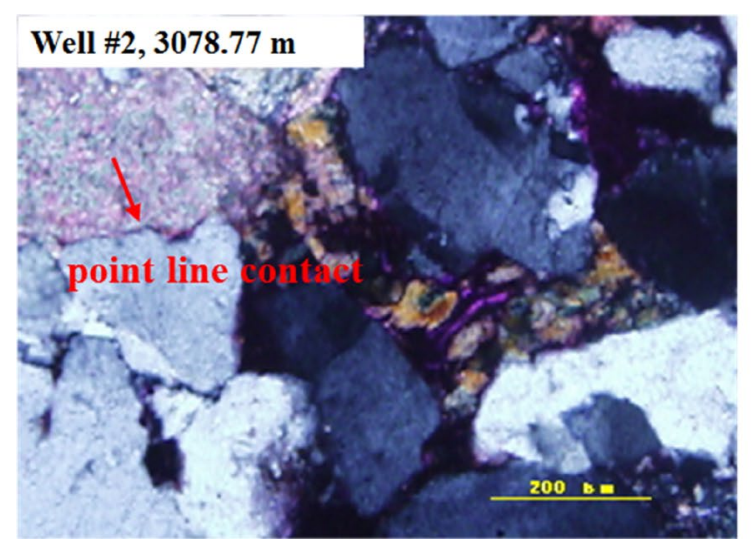

\section{Diagenesis}

Diagenesis has an important influence on the physical characteristics of rock, such as pore type, pore number, permeability, pore structure and distribution (Yong et al. 2011; Junmao and Ming 1989; Jianfeng et al. 2001; Jianping et al. 2010; Yuanlin et al. 2007; Xudong et al. 2017). It is a key acquired factor to determine the physical properties of reservoir. The Mesozoic diagenesis in the eastern depression of North Yellow Sea basin is strong, which makes the Mesozoic reservoir become very tight. Illite is the main clay mineral, followed by kaolinite and chlorite. The content of smectite is relatively small. The content of montmorillonite, vitrinite reflectance $\left(R_{O}\right)$ and maximum pyrolysis temperature (Tmax) of organic matter in the illite and montmorillonite mixed layer are $10-30 \%, 0.67-1.05 \%$ and $426-446^{\circ} \mathrm{C}$, respectively. Part of the shallow Cretaceous is in early diagenetic stage $B$, and vitrinite reflectance $\left(R_{O}\right)$ of organic matter is less than $0.35 \%$, which is in immature stage. Kaolinite of Cretaceous system generally increases with the increase in depth, chlorite and siderite are rare, and feldspar clayization is more. In this study, compaction, cementation and dissolution are the main diagenesis that have great influence on reservoir physical properties.

\section{Compaction}

Compaction is an important factor for porosity reduction. With the increase in compaction strength, the particles gradually change from floating to point contact, point line contact, line contact, mosaic structure, which makes the original space reduce or even disappear, and it is irreversible. In this study area, the mechanical compaction is strong due to low texture maturity and compositional maturity of rocks. The contact relationship between particles is mainly linear contact, followed by point line contact, and some of them have concave convex contact (Fig. 8). In the cathodoluminescence

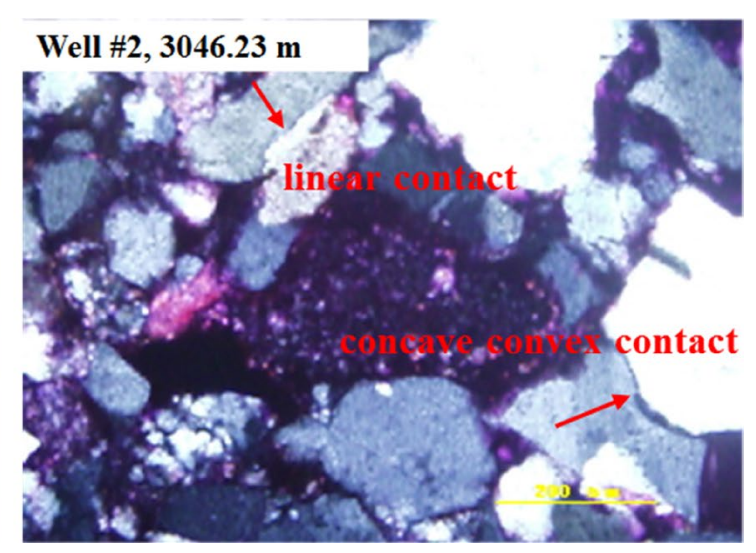

Fig. 8 Linear contact relationship of Lower Cretaceous reservoir particles

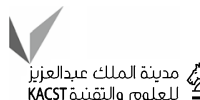
Springer 
of rock samples at the depth of $2293.05 \mathrm{~m}$ in well 3, it can be seen that the quartz particles suffer from compression and destroy, so the physical properties of Cretaceous system become worse due to the strong compaction, even some reservoirs have no pore development.

\section{Cementation}

The cement will reduce the pore space and block the throat, resulting in the decrease in porosity and permeability. In this study area, the content of Cretaceous cements is generally $3-37 \%$, with an average of $10.38 \%$ (Shukunl et al. 2010). The cements include calcite, dolomite, argillaceous, kaolinite, illite, and siliceous, etc. The Cretaceous reservoirs are mainly composed of calcite, dolomite and argillaceous cements. The content of calcite is generally $1-20 \%$, some more than $20 \%$, the content of dolomite is generally $3-14 \%$, and the content of argillaceous is generally $1-8 \%$. Also, the cement of kaolinite, illite, siliceous and siderite can be seen in the Cretaceous reservoir (Fig. 9). Therefore, strong cementation results in poor porosity in the reservoir. But calcite cementation can dissolve and form intercrystallite pores under certain conditions, which is reversible.

\section{Dissolution}

Dissolution is a constructive diagenesis to improve reservoir physical properties in different formations (Zhou et al. 2019). The dissolution would process produce intragranular dissolution pores, rib-shaped dissolution pores, feldspar cleavage network dissolution pores, intracrystalline pores and cemented dissolution pores (Fig. 3). From the previous analysis of reservoir pore types (Fig. 4), it can be seen that dissolution pores account for $62.5 \%$ of reservoir space on average, which plays an important role in improving the reservoir. In addition, the solution expansion fractures formed by the dissolution expansion of structural fractures also play a significant role in improving the reservoir performance, forming fracture-dissolution pores, accounting for $21.43 \%$.

\section{Tectonism}

Fracture system is closely related to macro-fracture system. Fracture is of great significance to make up for poor reservoir physical properties and promote oil and gas migration and accumulation (Hua et al. 2007; Zhanli et al. 2014; Sun et al. 2020, 2019). Affected by Yanshan movement, the North Yellow Sea Basin experienced tectonic compression
Fig. 9 Filling characteristics of cement in Lower Cretaceous Reservoir

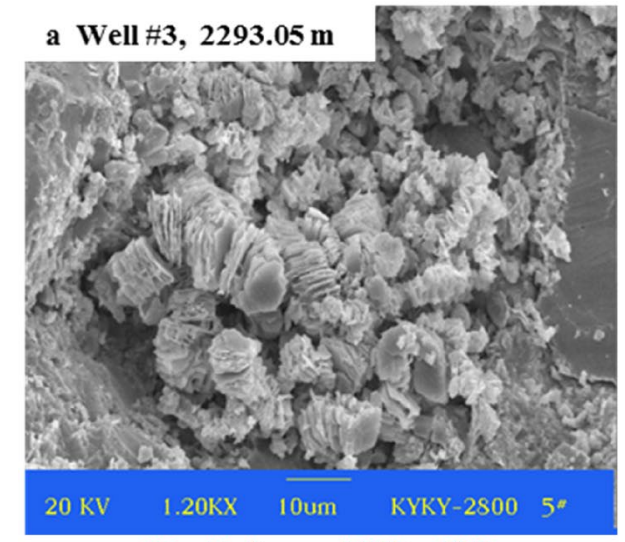

a Kaolinite and illite filling

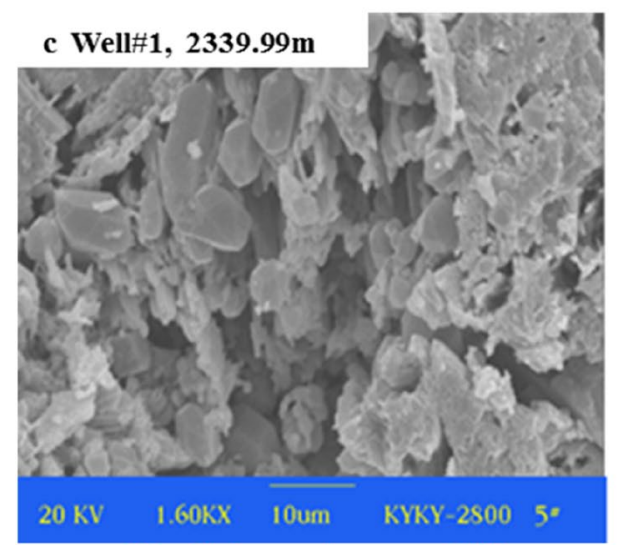

c Kaolinite and quartz filling

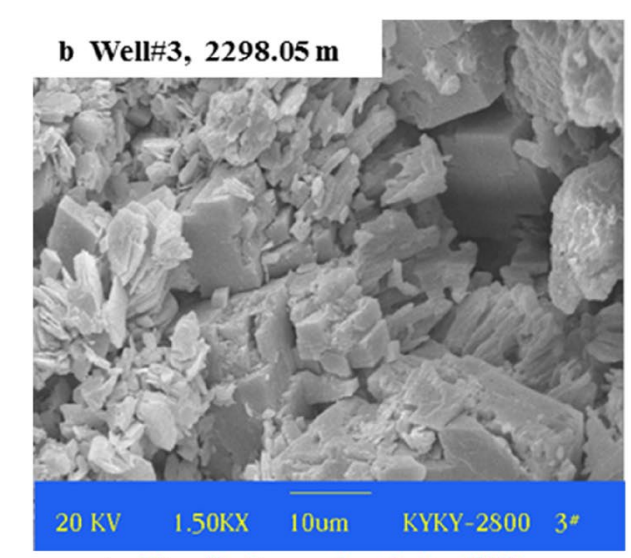

b Kaolinite and calcite filling

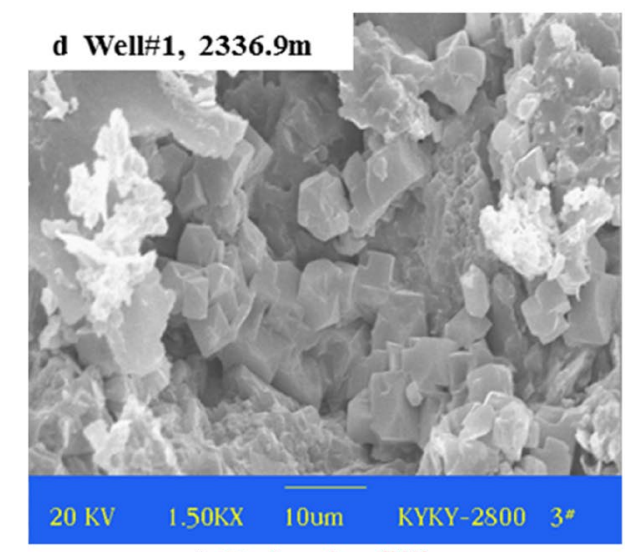

d Dolomite filling

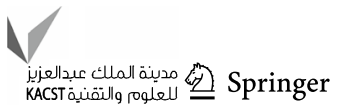




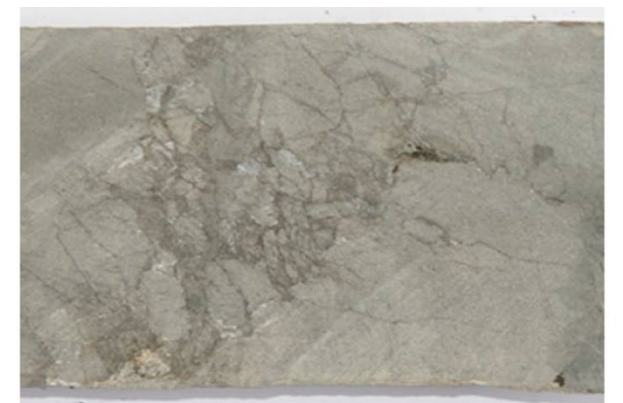

a Vertical fracture, in the depth of $2546.95 \mathrm{~m}$

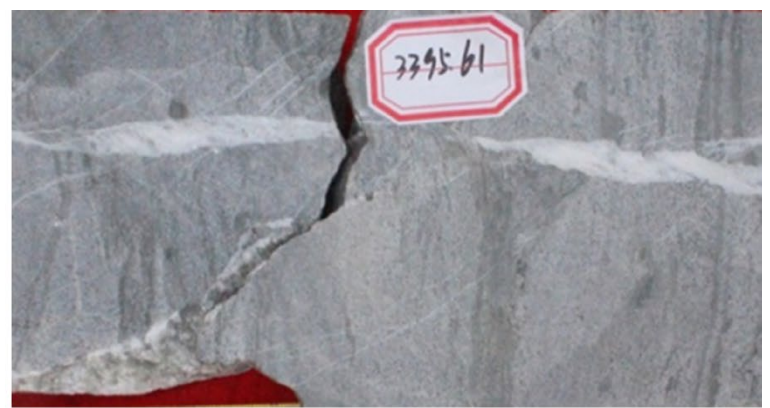

b Vertical fracture, in the depth of $3395.61 \mathrm{~m}$

Fig. 10 Fracture characteristics of Cretaceous reservoir core

Fig. 11 Imaging logging characteristics of fracture development in Cretaceous Reservoir

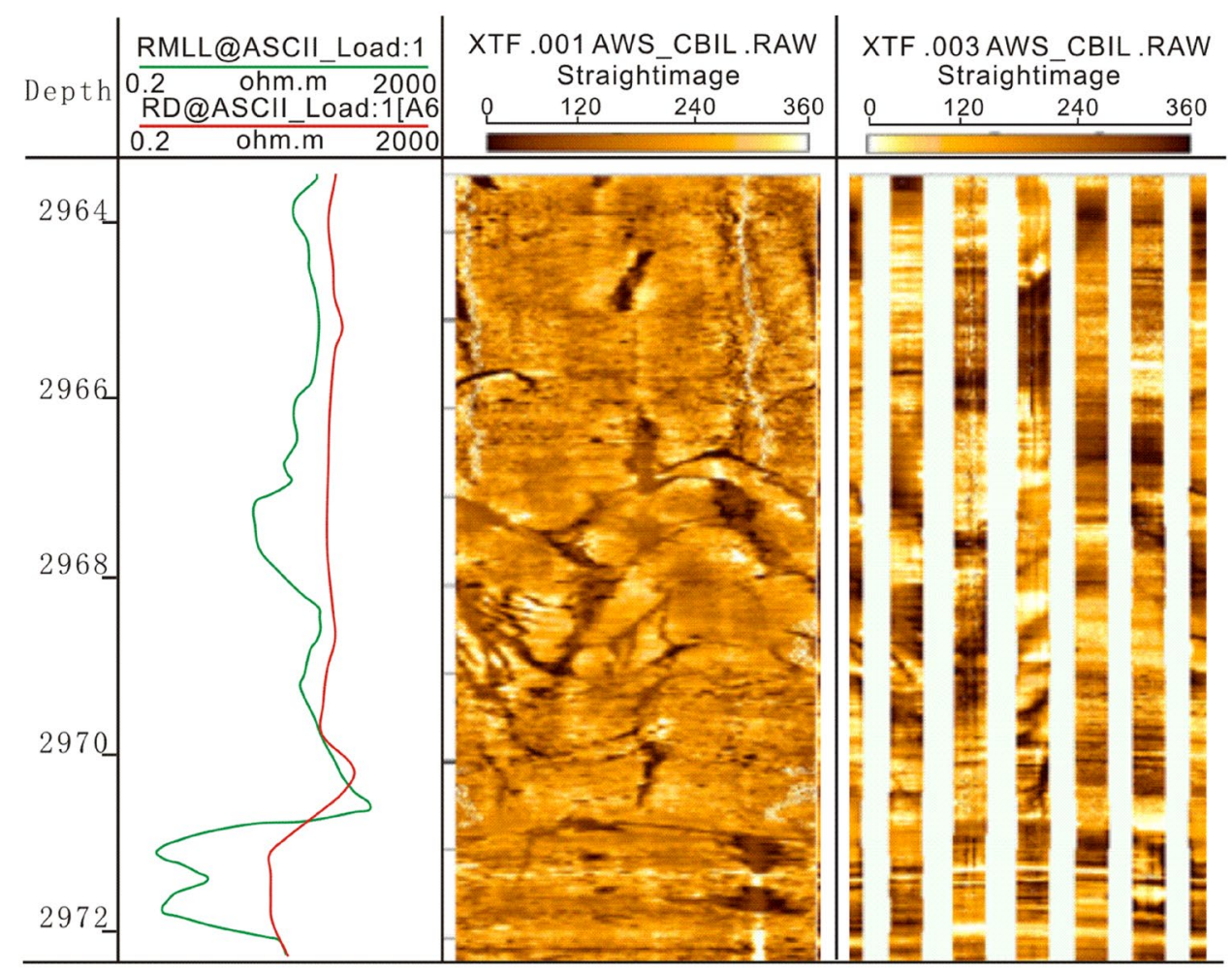

and uplift in the late Cretaceous, causing the reservoir to be cracked and develop fracture, which improved the reservoir conditions. Under the influence of Himalayan movement in the late Cretaceous, the tectonic uplift occurred again in the upper Oligocene and the strata were compressed, resulting in the strong structural deformation in the local area, which made the reservoir reformed again and strengthened the development of fractures. Based on most core observations and Cretaceous imaging logging, fractures are developed in Cretaceous reservoir, with high angle fractures (Fig. 10 Fig. 11 and Fig. 12). On the one hand, the micro-fractures produced by tectonism can form reservoir space; on the other hand, they play a role of connecting reservoir pores and improve reservoir permeability effectively.

\section{Conclusions}

1) The Cretaceous reservoirs in the eastern depression of the North Yellow Sea basin are characterized by low compositional maturity and texture maturity. The rocks are mainly composed of lithic arkose, arkose, some feldspathic sandstone and a small amount of lithic sandstone. The rock sorting is poor to medium, some are better, and the rock particles are mainly sub-angular and sub-circular.

2) The physical property of Cretaceous reservoir is poor, which belongs to low porosity and low permeability reservoir. The porosity is concentrated in $2-10 \%$, and 


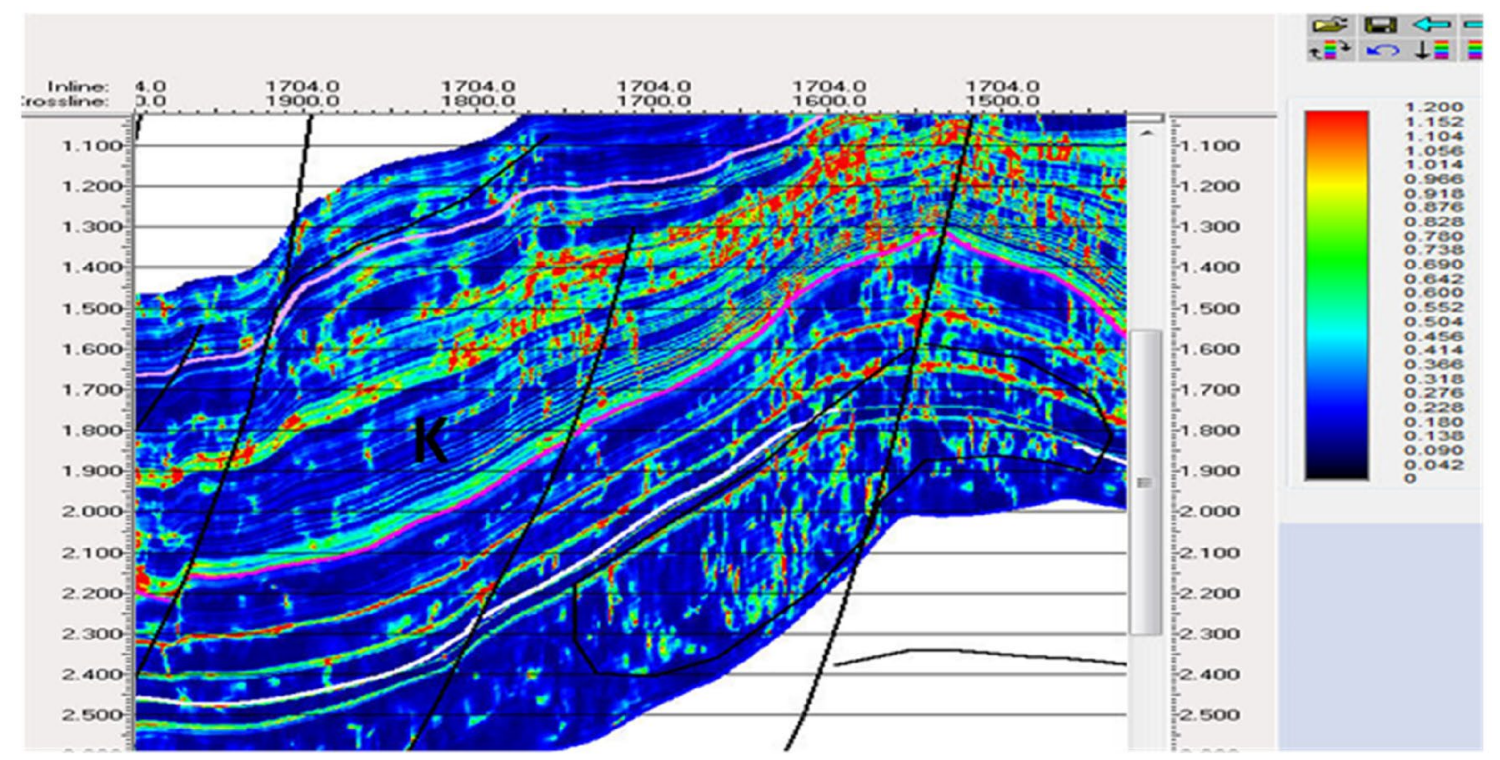

Fig. 12 Seismic curvature fracture density prediction profile in Cretaceous Reservoir

the permeability is mostly less than $1 \times 10^{-3} \mu \mathrm{m}^{2}$. The permeability of a small part is greater than $1 \times 10^{-3} \mu \mathrm{m}^{2}$. The physical properties of shallow-buried reservoirs are better, and the porosity is more than $10 \%$. The Cretaceous reservoir is characterized by high mercury injection displacement pressure, small pore throat, poor connectivity, uneven distribution, small mercury inflow, poor pore structure and strong heterogeneity.

3) The Cretaceous reservoir is mainly composed of secondary pores, mainly dissolution pores, some fractures, a small number of intercrystalline pores, and little or no primary pores.

4) The main factors that affect the physical properties of Cretaceous reservoir are sediment provenance, sedimentation, diagenesis and tectonism. The provenance properties and sedimentary facies types are the prerequisite conditions for reservoir material. The physical properties of arkose and lithic arkose with high feldspar content are better than those of feldspar lithic sandstone and lithic sandstone with relatively high lithic content. The physical properties of braided delta front underwater distributary channel and shore shallow lake sand bar reflecting strong hydrodynamic conditions are relatively good, while the physical properties of braided delta front or flank and shore shallow lake sheet sand reservoir reflecting relatively weak hydrodynamic conditions are poor. Mechanical compaction and cementation strengthen the density of the reservoir, while dissolution and tectonism improve the physical conditions of the reservoir, thus forming the reservoir characteristics of secondary pores in the study area.
Acknowledgements We thank the editors and anonymous referees for their helpful comments improving this contribution. This study is financially supported by the National Natural Science Foundation of China (42076220), the National Natural Science Foundation of Shandong province in China (ZR2020QD038, ZR2020MD071), oil and gas geological survey in key sea areas (DD20211353), and survey in upwarping zone of Laoshan (DD20190818).

Funding This study is financially supported by the National Natural Science Foundation of China (42076220), the National Natural Science Foundation of Shandong province in China (ZR2020QD038, ZR2020MD071), oil and gas geological survey in key sea areas (DD20211353), and survey in upwarping zone of Laoshan (DD20190818).

\section{Declarations}

Conflict of interests The authors declare that there is no conflict of interest regarding the publication of this paper.

Ethical statement On behalf of all the co-authors, the corresponding author states that there are no ethical statements contained in the manuscripts.

Open Access This article is licensed under a Creative Commons Attribution 4.0 International License, which permits use, sharing, adaptation, distribution and reproduction in any medium or format, as long as you give appropriate credit to the original author(s) and the source, provide a link to the Creative Commons licence, and indicate if changes were made. The images or other third party material in this article are included in the article's Creative Commons licence, unless indicated otherwise in a credit line to the material. If material is not included in the article's Creative Commons licence and your intended use is not permitted by statutory regulation or exceeds the permitted use, you will need to obtain permission directly from the copyright holder. To view a copy of this licence, visit http://creativecommons.org/licenses/by/4.0/. 


\section{References}

Li Feng jie, Wang Duoyun, Xu Hui (2005) The influential factors and characteristics of triassic yanchang formation reserviorin longdong area, ordos basin. 27(4): 367-369

Gai-yun W, Jin-ping L, Jian Xiao-ling Du, Min. (2016) Sedimentary filling and favorable source-reservoir-seal rock assemblage of Mesozoic in the North Yellow Sea Basin [J]. Geol Explor 52(1):0191-0198

Zhenhu Liu, Gao hongfang, Hu Xiaoqiang, et al (2007) A study on the Mesozoic petroleum system in East depression, North Yellow Sea Basin. China Offshore Oil and Gas 19(4):229-233

Hua Y, Xianyang L, Caili Z et al (2007) The main controlling factors and distribution of low permeability lithologic reservoirs of Trias-sic Yanchang Formation in Ordos Basin [J]. Lithologic Reservoirs 19(3): 1-6

Jianfeng Shou, Chunsong Si, Guohua Zhu et al (2001) Control factors of the properties of the Lower Jurassic sandstone reservoirs in the Kuqa Depression. Tarim Basin Geolo Rev 47(3):272-277

Jiangqi He, Shiyou L, Yongqiang Z et al (2007) Characteristics of geologic structures of the Northyellow Sea Basin: implications for petroleum exploration. Mar Geol Q Geol 27(2):101-102

Jianping Yan, Chiyang Liu, Weigang Zhang et al (2010) Diagenetie characteristics of the lower porosity and permeability sandstones of the Upper Paleozoic in the south of Ordos Basin. Acta Geologica Sinica 84(2):272-279

Jie C (2005) Potential analysis of exploration for pre Cenozoic marine residual basins in Northern Yellow Sea. Prog Geophys 20(3):757-760

Jinping L, Gaiyun W, Liaoliang W et al (2015) Main controlling factors of hydrocarbon accumulation in the Eastern Sub-basin, North Yellow Sea. Oil Gas Geol 36(6):888-889

Zheng Junmao,Pang Ming (1989) Study on clastic diagenesis. Wuhan:China University of Geosciences Press, 15-85

Li Z, Yongzhang Z, Liaoliang W et al (2009) Nat Gas Ind 29(1):21-25

Lin C, Zhilin B, Wenyong Li (2006) Geophysical Prospecting for Petroleum 45(3):319-323

Min Du, Gaiyun W, Jinping L et al (2014) Stratigraphic division and sedimentary characteristics of the eastern depression of the North Yellow Sea Basin 1. Special Oil Gas Reserv 21(2):51-56

Min Du, Houjin W, Gaiyun W, Xiaoling J, Xiaoming W (2016) Characteristics and formation mechanism of meso-cenozoic superimposed basins in the East Depression of the North Yellow Sea Basin[J]. Mar Geol Q Geol 36(5):85-96 ((in Chinese with English abstract))

Ren W, Wanzhong S, Dan X et al (2015) Architecture Characteristics and Control Factors of Lower Cretaceous Sequence in North Yellow Sea Basin. Acta Petrolei Sinica 36(12):1531-1540

Shiyoul L, Li Fengli Fu, Jie, et al (2009) Evaluation of meso-cenozoic hydrocarbon source rocks in NorthYellow Sea Basin. Pet Geol Exp 31(3):249-251

Shukunl Yuan, Yingminz Wang, Zhenhu Liu et al (2010) Unconformity types and hydrocarbon accumulation models in the eastern depression of the North Yellow Sea basin. Petrol Explor Develop 37(6):663-667

Sun Yu, Haitao Yu, Shizhong Ma et al (2017) Physical Property of Tight Sandstone Reservoir and Its Controlting Factors: A Case Study of the Fourth Member of Cretaceous Quantou Formation in Da\&apos;an Area of Songliao Basin. J China Univ Min Technol 46(4):810-817

Sun Z, Shi J, Wu K, Zhang T, Feng D, Li X (2019) Effect of pressurepropagation behavior on production performance: implication for advancing low-permeability coalbed-methane recovery. SPE J 24(02):681-697

Sun Z, Li X, Liu W, Zhang T, He M, Nasrabadi H (2020) Molecular Dynamics of Methane Flow Behavior through Realistic Organic
Nanopores under Geologic Shale Condition Pore size and Kerogen Types. Chem Eng J 398:124341

Sun Z, Wang S, Xiong H, Wu K, Shi J (2021a) Optimal nanocone geometry for water flow. AIChE J. https://doi.org/10.1002/aic. 17543

Sun Z, Huang B, Li Y, Lin H, Shi S, Yu W (2021b) Nanoconfined methane flow behavior through realistic organic shale matrix under displacement pressure: a molecular simulation investigation. J Petrol Explor Prod Technol. https://doi.org/10.1007/ s13202-021-01382-0

Sun Z, Huang B, Li Y, Yu W, Ji L (2022) Production forecast of fractured vertical wells in coalbed methane reservoirs: coupling dynamic drainage area. Arab J Geosci 15:7. https://doi.org/10. 1007/s12517-021-09094-9

Wenyong Li, Dongxu Li, Bin X et al (2006a) Charactereistics of Structural Evolution in North Yellow Sea Basin. Geoscience 20(2):269-275

Wenyong LI, Dongxu LI, Houjin Wang (2006) New progress in the study of tectonic geometry of the North Yellow Sea Basin. J Geomech 12(1):12-21

Wenyong LI, Xianghui Zeng, Jiajian Huang (2009) Meso-Cenozoic North Yellow Sea: Residual Basin or Superimposed Basin? Acta Geologica Sinica 83(9):1269-1274

Xiaoqiang Hu, Yanjie S, Dan G, Gaiyun W, Rihui C (2015) Filled characteristics of depositional sequence and evolution of Eastern Sag in North Yellow Sea Basin[J]. Global Geology 34(4):1042-1051

Xiaoqiang Hu, Daqing T, Liaoliang W, Wang Houjin Du, Min. (2017) Fault structures in the Eastern Depression of the North Yellow Sea Basin[J]. Geological Science and Technology Information 36(1):117-127

Xudong W, Xiangtao Z, Min He et al (2017) Characteristics and controlling factors of reservoir development in the Wenchang Formation, Southern Lufeng Sag, Pearl River Mouth Basin. Oil Gas Geol 38(6):1147-1155

Yanzhong W, Yingchang C, Shiyue C et al (2007) Clastic Reservoirs Characteristics and Control of Mesozoic in Jiyang Depression. J China Univ Petrol 31(5):7-17

Yi Wang, Junfei LI, Jiaqiong PENG et al (2020) Fine analysis of sedimentary facies and main controlling factors of reservoir in the first sand group of 1st member of Cretaceous Qingshuihe Formation in SN31 well area of Junggar Basin. Natural Gas Geosci 31(2):194-208

Yong Z, Youlian Ji, Shanwen Z et al (2011) Characteristics and controlling factors on physical properties of low-permeability sandstones of the Laiyang Formation in the Laiyang Sag. Jiaolai Basin Acta Petrolei Sinica 32(4):17-26

Yonghong Li, Xiangbin Y, Tao Z (2004) Reservoir Characteristics and Their Controlling Factors of the Carboniferous Karashayi Formation in Tahe Olilfield. Pet Geol Exp 26(1):17-26

Yuanlin M, Yuechuan W, Jiayu N et al (2007) Prediction of reservoir porosity and determination of effective gas reservoirst Taking Yuanyanggou area of Bohai Bay Basin as an exampleEJ]. Nat Gas Ind 27(6):42-44

Zhanli R, Wenhou Li, Liang Yu et al (2014) Tight oil reservoir formation conditions and main controlling factors of Yanchang Formation in southeastern Ordos Basin [J]. Oil Gas Geol 35(2):190-198

Zhenhu L, Feiyu W, Jinping L et al (2014) Time of hydrocarbon accumulation in eastern depression of North Yellow Sea Basin. Pet Geol Exp 36(5):550-554

Zhou Lv, Yupu W, Youjing W et al (2019) Controlling Factors on Physical Properties of Cretaceous Nahr Umr Formation Sandstone Reservoir in Halfaya Oilfield, Iraq[J]. J Earth Sci Environ 41(6):707-720 